\title{
Survey evaluation of in-hospital diabetes seminars provided by medical professionals, for medical professionals
}

This article was published in the following Dove Press journal: Journal of Multidisciplinary Healthcare

\author{
Miyako Kishimoto ${ }^{1,2}$ \\ 'Clinical Research Center, Department of \\ Medicine, International University of \\ Health and Welfare, Tokyo, Japan; \\ ${ }^{2}$ Department of Internal Medicine, Sanno \\ Hospital, Tokyo, Japan
}

Purpose: Diabetes is a multifactorial disease, and interprofessional teamwork is essential for its treatment. For successful interprofessional teamwork, individual medical professionals need to have certain skills, experience, and mutual understanding of the role of different professions. However, there are few opportunities to educate medical professionals to meet these demands. To resolve this problem, educational seminars about diabetes were conducted by and for medical professionals, and their effects were assessed using a questionnaire survey.

Participants and methods: Medical professionals, including a dietician, a physiotherapist, a pharmacist, a clinical laboratory technician, and a doctor, provided 10 lectures, approximately 50 mins each, for medical professionals about their specialized skills in diabetes care. Nurses who were certified diabetes educators in Japan planned and organized the seminars. In every seminar, participants were asked to complete a questionnaire regarding their profession, motivation to attend the seminar, general comments about the seminar, expectations regarding future seminars, and effects of the seminar on their daily work or attitude toward patients.

Results: Among the 367 participants, 332 completed the questionnaire (respondents). The results revealed that by attending the seminars, some respondents strongly realized their lack of knowledge, some were inspired and encouraged to study more about diabetes, and some could understand other professions' work in diabetes care better than before. Over $70 \%$ of respondents reported that attending the seminar had changed their daily work or attitude toward patients; the remainder, however, felt unchanged for reasons such as their own lack of experience and ability, and the few chances to aid patients with diabetes.

Conclusion: Educational diabetes seminars by and for medical professionals were implemented. The survey of the effects of the seminar has provided further insights into the needs and current situation of education for medical professionals.

Keywords: diabetes, educational seminar, interprofessional teamwork, questionnaire

\section{Introduction}

The number of people with diabetes has rapidly increased worldwide. According to the statistics of the International Diabetes Federation, there are 425 million people with diabetes in the world, which is projected to reach 629 million in 2045. ${ }^{1}$ To provide appropriate medical care for increasingly more patients with diabetes, and also because of the multifactorial nature of this disease, doctors and all health care providers involved in diabetes care should work together to provide comprehensive and effective diabetes services. ${ }^{2-7}$ An interprofessional team approach is essential for adequate patient care; in
Correspondence: Miyako Kishimoto Clinical Research Center, Department of Medicine, International University of Health and Welfare, 8-10-16 Akasaka Minato, Tokyo 107-0052, Japan

Tel +8 I33 4023 3II I

Fax +8 I334043652

Email mkishimoto@iuhw.ac.jp 
fact, interprofessional collaboration has been reported to improve outcomes in patients with diabetes. ${ }^{8-19}$

To successfully adopt an interprofessional team approach, all team members require continuous professional training to maintain their ability to provide the best diabetes care, adopting up-to-date medical advances in the field that might affect patients' daily diabetes management. ${ }^{11,20}$ In addition, mutual respect and understanding of other professions are necessary for smooth interprofessional collaboration. However, due to the tight schedule of their own daily practice, it is difficult for health care professionals to keep up with the latest diabetes information, especially with issues that are not in their own field; moreover, due to a lack of time and opportunity, the chances to observe other health care professions' practice or provision of patient education are unfortunately scarce. To address this issue, our hospital conducted periodic educational seminars about diabetes, which were presented by and for medical professionals at our hospital. Here, we report the results of a questionnaire survey evaluating the effect of the seminars on participants and propose a vision for the future education of medical professionals.

\section{Material and methods}

From June 2015 to February 2016, a doctor provided three lectures on diabetes in general (pathophysiology, diagnosis, examinations, complications, treatments, and education for patients with diabetes) to medical professionals at Sanno Hospital. After medical professionals acquired basic knowledge about diabetes in these lectures, a series of 10 educational seminars were provided by medical professionals, including a registered dietician, physiotherapist, pharmacist, clinical laboratory technician, and doctor, from May 2016 (1st seminar) to March 2018 (10th seminar). Each seminar included a lecture of approximately 50 mins given by various professionals and short supplementary comments from doctors. The lecturers talked about their own professional field with slides and handouts. Often, the lectures included case studies of real patients with diabetes to help participants better understand the content through a sense of familiarity and practicality. In the 9th seminar, participants practiced self-monitoring of blood glucose (SMBG). Nurses who were certified diabetes educators in Japan (CDEJ) planned and organized the seminars.

Sanno Hospital is a private hospital with multiple clinical departments, which specializes in infertility treatment
Table I Seminar topics and professions of lecturers

\begin{tabular}{|l|l|l|}
\hline No. & Title of lecture & Lecturer profession \\
\hline Ist & Diet therapy for diabetes & Dietician \\
2nd & Exercise therapy for diabetes & Physiotherapist \\
3rd & Pharmacotherapy for diabetes & Pharmacist \\
4th & Examination for diabetes & Clinical laboratory \\
& & technician \\
5th & Gestational diabetes & Diabetologist \\
6th & Exercise therapy: case study & Physiotherapist \\
7th & Diet therapy for diabetic & Dietician \\
& nephropathy & \\
8th & Pharmacotherapy: cautionary & Pharmacist \\
& points & \\
9th & Self-monitoring of blood glucose & Clinical laboratory \\
& (SMBG) & technician \\
10th & Patient education & Diabetologist \\
\hline
\end{tabular}

and pregnancy care; thus, it is recognized as a maternity hospital. The hospital annually treats an average of 1,172 pregnant women, of which $98(8.36 \%)$ are annually diagnosed with gestational diabetes on average. Thus, medical professionals working at this hospital require a certain level of knowledge and experience with gestational diabetes. Therefore, gestational diabetes was included in the lecture topics (Table 1), and midwives participated in the seminars.

The seminar participants were asked to complete a questionnaire comprising 8 questions (Q1-Q8) (Table 2). Q2 was only answered by participants attending the 1st to the 5th seminar. In addition to Q1 and Q3-Q5, participants attending the 6th to the10th seminar were asked to answer Q6, which required a "yes/no" response. Those who answered "yes" to Q6 were asked to answer Q7, which required a "yes/no/not sure" response. Those who answered Q7 also answered Q8. All the seminars were conducted in a free-for-all style. The questionnaire was anonymous and

Table 2 Questions included on the questionnaire form
(QI) "What is your profession?"
(Q2) "Why did you decide to attend this seminar?"
(Q3) "What topics impressed you in today's seminar?"
(Q4) "What topics do you prefer for the next seminar?"
(Q5) "Please write your free and general comments for today's seminar."
(Q6) "Have you attended the previous seminar?"
(Q7) "After you attended the seminar, do you think there were some changes in your daily work or your attitude towards your patients?" (Q8) "Why do you think so? Please explain the reasons for this." 
completion was voluntary. Substantially similar answers for Q2 were grouped and categorized into themes. Similar answers to Q5 and Q8 were also grouped.

The survey has been approved by the Ethics Committee of Sanno Hospital. Informed consent was obtained from all participants.

\section{Results}

Table 1 shows the seminar topics and professions of lecturers for all 10 seminars. Each seminar was attended by 29-50 (average 36.7) participants, and among the 367 total participants (ie, the cumulative total number of 10 seminars), 332 completed the questionnaire (respondents). The response rates to the questionnaires for each seminar were 83.9-97.6\%. According to the answers to Q1, the number and percentages of each occupation of respondents were as follows: nurses, 158 (47.6\%); pharmacists, 44 (13.3\%); physiotherapists, 34 (10.2\%); clinical laboratory technicians, 28 (8.4\%); midwives, 28 (8.4\%); dieticians, 20 (6.0\%); and doctors, 20 (6.0\%).

The answers to Q2 (reasons to attend seminars) for all professions were grouped and categorized (Table 3). The answers to Q3 were varied (data not shown), suggesting that participants were interested in and impressed by diverse topics in the lectures. Regarding Q4, the typical (top 5) preferred seminar topics from each profession are listed in Table 4. The representative answers to Q5 (general comments about seminars) for each profession are shown in Table 5.

As for Q6 (attended previous seminar), among all the participants of the 6th to the 10th seminar (151 respondents in total), $88(58.3 \%)$ answered "yes." Among those 88 , a total of $64(72.7 \%)$ (in all professions) answered "yes" to Q7 (changes in practice/attitude). Answers to Q7 for each profession are shown in Table 6. Substantially similar answers to Q8 (reasons for answering Q7) were grouped, and representative answers of each profession are shown in Table 7.

\section{Discussion}

This study involved a questionnaire survey to evaluate educational diabetes seminars provided by and for medical professionals at Sanno Hospital. It was revealed that most of the participants attended the seminar spontaneously with an eagerness to gain knowledge about diabetes, pure interest in the lecture topics, or out of necessity (Table 3 ). The responses regarding preferred topics for future seminars indicated that almost all professional groups expected case studies, and pharmacists, physiotherapists, dieticians, and midwives listed "gestational diabetes," probably because they encountered many of these patients in their daily practice (Table 4). Regarding the free and general comments, some respondents strongly realized their lack of knowledge, and some were inspired and encouraged by the seminar to study more about diabetes (Table 5). Some respondents commented that through the seminars, they could understand other professions' work in diabetes care better than before. This was actually one of the aims of the seminars provided by and for multiple medical professionals. In order to implement effective interprofessional teamwork, medical professionals from different professions need to educate and inform each other.

Besides attending lectures, participants also practiced SMBG. This experience seemed to be impressive for the participants, realizing how painful and troublesome SMBG can be for patients who have to do many times a day for many years. Therefore, interactive participatory seminars like ours will be valuable.

From the participants who attended the latter half of the seminar series, more than $70 \%$ in all the professions except pharmacists and clinical laboratory technicians reported that the seminar they had already attended changed their daily work or attitude toward their patients (Q7) (Table 6). Reasons for responding "No" or "Not sure" to this question included lack of experience, shortage of ability, and few chances to use the knowledge acquired

Table 3 Answers of all professionals to Q2 ("Why did you decide to attend this seminar?")

\begin{tabular}{|l|l|l|l|l|l|l|}
\hline Seminar No. & Ist & 2nd & 3rd & 4th & 5th & Total (\%) \\
\hline I want to gain knowledge about diabetes & 40 & 37 & 18 & 26 & 7 & $128(55.4)$ \\
I'm interested in the topics & 0 & 12 & 7 & 6 & 29 & $54(23.4)$ \\
I'm in charge of patients with diabetes & 0 & 0 & 15 & 4 & 13 & $32(13.9)$ \\
The previous seminars were helpful & 0 & 0 & 0 & 3 & 4 & $7(3.0)$ \\
I want to use the knowledge about diabetes for myself & 3 & 0 & 0 & 0 & 2 & $5(2.2)$ \\
My colleague/chief gives a lecture & 0 & 1 & 2 & 0 & 0 & $3(1.3)$ \\
I was recommended to participate & 1 & 1 & 0 & 0 & 0 & $2(0.9)$ \\
\hline
\end{tabular}

Note: Each column indicates numbers of respondents. 
Table 4 Answers of each profession to Q4 ("What topics do you prefer for the next seminar?")

\begin{tabular}{|c|c|}
\hline Profession & Top 5 preferred seminar topics \\
\hline Nurses & $\begin{array}{l}\text { (1) Exercise therapy } \\
\text { (2) Education for diabetic patients } \\
\text { (3) Medication } \\
\text { (4) Diet therapy } \\
\text { (5) Case study }\end{array}$ \\
\hline Pharmacists & $\begin{array}{l}\text { (1) Drug selection for individual patients } \\
\text { (2) Case study } \\
\text { (3) Gestational diabetes } \\
\text { (4) Diet therapy } \\
\text { (5) Examinations regarding diabetes }\end{array}$ \\
\hline Physiotherapists & $\begin{array}{l}\text { (1) Case study } \\
\text { (2) Medication } \\
\text { (3) Diet therapy } \\
\text { (4) How to prevent diabetes onset } \\
\text { (5) Gestational diabetes }\end{array}$ \\
\hline $\begin{array}{l}\text { Clinical laboratory } \\
\text { technicians }\end{array}$ & $\begin{array}{l}\text { (I) Education for diabetic patients } \\
\text { (2) Diabetic complications } \\
\text { (3) Case study } \\
\text { (4) How to prevent diabetes onset } \\
\text { (5) Diet therapy }\end{array}$ \\
\hline Dieticians & $\begin{array}{l}\text { (1) Exercise therapy } \\
\text { (2) Other professions' activity regarding } \\
\text { diabetes care } \\
\text { (3) Case study } \\
\text { (4) Any topic will be helpful } \\
\text { (5) Gestational diabetes }\end{array}$ \\
\hline Midwives & $\begin{array}{l}\text { (I) Gestational diabetes } \\
\text { (2) Insulin therapy } \\
\text { (3) Diet therapy } \\
\text { (4) Alcohol and diabetes } \\
\text { (5) Hypoglycemia }\end{array}$ \\
\hline Doctors & $\begin{array}{l}\text { (1) Medication } \\
\text { (2) Case study } \\
\text { (3) Diabetic complications } \\
\text { (4) Treatment for acute phase diabetes } \\
\text { (5) New device for self-monitoring } \\
\text { blood glucose }\end{array}$ \\
\hline
\end{tabular}

in the seminar with real patients (Q8) (Table 7). Given the nature of their profession, clinical laboratory technicians have less opportunities to be directly involved in patients' diabetes care. Among the various medical professionals, nurses are supposed to be the most involved in patient care. However, the answers of some nurses, such as "Lectures were helpful but I did not have a chance to use the knowledge I gained" or "I am still inexperienced and I haven't had many opportunities to aid patients with diabetes," indicate that seminar attendance alone did not change their daily work or attitude toward patients. If the problem is solely their limited personal ability, improvements can be made through individual effort. If the problem is that medical personnel want to care more for patients with diabetes but cannot do so because of mismatched allocation, individual facilities should reconsider the medical professional's allocation so that they may have more of a chance to see patients with diabetes and to improve their skills in caring for such patients.

The seminars were mainly planned and organized by nurses who were certified diabetes educators of Japan (CDEJ). CDEJ is a qualification awarded in Japan to nurses, dietitians, pharmacists, clinical laboratory technicians, or physiotherapists possessing wide specialist knowledge and experience in diabetes. Currently, there are more than 19,500 CDEJs, mostly nurses (45.9\%), dieticians $(24.6 \%)$, and pharmacists $(15.4 \%){ }^{21}$ Incorporating diabetes educators into clinical services is expected to improve clinical and quality-of-life outcomes of persons with diabetes, ${ }^{22}$ and many medical professionals recognize the need for more diabetes educators such as diabetes specialist nurses. ${ }^{23}$ However, according to a previous survey with CDEJs, fewer than $40 \%$ of the responding CDEJs were satisfied with the current state of their activities and contributions as CDEJs. ${ }^{24}$ Many perceived that they were not working sufficiently, and the reasons identified for this included "low awareness of CDEJs" and "insufficient interprofessional teamwork." "24 In the present seminar, CDEJs prepared and disseminated information to other medical professionals, and this might be a good opportunity to improve awareness of CDEJs by other medical professionals. As for "insufficient interprofessional teamwork," by participating in the seminar, medical professionals might get acquainted with each other, and through the lectures, participants might deepen their understanding of other professions' skills and activities. All of these possibilities may lead to better interprofessional teamwork so that CDEJs can show their strength sufficiently and effectively in the team.

There are some limitations to the present study. First, because this survey was carried out at a single medical center (maternity hospital), the results of the survey may not be generalizable to other medical institutions. Second, because the questionnaire was completed by the participants of educational diabetes seminars, who might be more enthusiastic and motivated about diabetes care than those who did not attend 
Table 5 Representative answers of each profession to Q5 (“Please write your free and general comments for today's seminar")

\begin{tabular}{|c|c|}
\hline Profession & Representative general comments \\
\hline Nurses & $\begin{array}{l}\text { - Case study was informative and helps me to understand. } \\
\text { - The lecture was helpful not only for patients but also for myself and my family. } \\
\text { - By attending the seminar, I realized that my knowledge is insufficient. } \\
\text { - After attending the seminar, I feel like I want to learn more about diabetes. } \\
\text { - It was unfortunate and disappointing that some other nurses did not attend the seminar. } \\
\text { - This is the first time that I experienced SMBG by myself. It was painful and I think it was a good opportunity for } \\
\text { me to understand patients' pain and suffering. }\end{array}$ \\
\hline Pharmacists & $\begin{array}{l}\text { - So many new drugs come out to the market one after another. I felt that day-to-day learning is necessary. } \\
\text { - The lecture was educational and I feel like I want to study more about diabetes. }\end{array}$ \\
\hline Physiotherapists & $\begin{array}{l}\text { - The lecture was very helpful. I want to use the knowledge that I acquired today in my job. } \\
\text { - It was a good opportunity to reconsider diet therapy together with exercise therapy. }\end{array}$ \\
\hline $\begin{array}{l}\text { Clinical laboratory } \\
\text { technicians }\end{array}$ & $\begin{array}{l}\text { - I was stimulated by a lecture. Now I decided that I will continue to study. } \\
\text { - There were so many things that I felt I know but actually not. } \\
\text { - It is difficult to study about diabetes by myself from a basic level. Thus, the lectures were very helpful. } \\
\text { - It is good to know what other professions are doing and how they educate diabetic patients. }\end{array}$ \\
\hline Dieticians & $\begin{array}{l}\text { - Now I understand that communication with patients is very important during diet counselling. } \\
\text { - The lecture about education for diabetic patients made me feel that I would like to get close to patients. } \\
\text { - I could learn much more about diabetic nephropathy. } \\
\text { - Experiencing SMBG was a precious opportunity for me. }\end{array}$ \\
\hline Midwives & $\begin{array}{l}\text { - I could have a real picture of a patient through various case presentations. } \\
\text { - I'm now in charge of a patient who is receiving insulin therapy. Thus, a lecture about insulin was timely. } \\
\text { - I was inspired by a lecture and became motivated to study more about diabetes. } \\
\text { - I didn't know that SMBG is such a painful examination. Hope I can tell my patients how to reduce their pain at the } \\
\text { time of SMBG. }\end{array}$ \\
\hline Doctors & $\begin{array}{l}\text { - I was deeply impressed that all concerned were committed to the seminar enthusiastically. } \\
\text { - Case studies are interesting and easy to comprehend. } \\
\text { - The lectures were helpful to organize the knowledge. } \\
\text { - Good to know the perspective of physicians about gestational diabetes, which is different from that of ours } \\
\text { (obstetrician). } \\
\text { - By experiencing SMBG, now I understand that it is fearful and painful. That's more than I expected. }\end{array}$ \\
\hline
\end{tabular}

Abbreviation: SMBG, Self-monitoring of blood glucose.

Table 6 Answers of each profession to Q7 ("After you attended the seminar, do you think there were some changes in your daily work or your attitude towards your patients?”)

\begin{tabular}{|c|c|c|c|c|}
\hline Profession & Yes & No & Not sure & Nonresponse \\
\hline Nurses & 33 (7I.7\%) & $3(6.5 \%)$ & 7 (I5.2\%) & $3(6.5 \%)$ \\
\hline Pharmacists & $4(50.0 \%)$ & $\mathrm{I}(12.5 \%)$ & $\mathrm{I}(12.5 \%)$ & $2(25.0 \%)$ \\
\hline Physiotherapists & $5(100.0 \%)$ & $0(0.0 \%)$ & $0(0.0 \%)$ & $0(0.0 \%)$ \\
\hline Clinical laboratory technicians & $6(60.0 \%)$ & I (I0.0\%) & $3(30.0 \%)$ & $0(0.0 \%)$ \\
\hline Dieticians & $6(75.0 \%)$ & $0(0.0 \%)$ & $2(25.0 \%)$ & $0(0.0 \%)$ \\
\hline Midwives & $2(100.0 \%)$ & $0(0.0 \%)$ & $0(0.0 \%)$ & $0(0.0 \%)$ \\
\hline Doctors & 8 (88.9\%) & $0(0.0 \%)$ & $0(0.0 \%)$ & I (II.I\%) \\
\hline
\end{tabular}

Notes: The numbers in each column indicate the numbers and percentages within each profession of answering "Yes," "No," or "Not sure." The numbers and percentages of nonresponses were also recorded.

the seminars, the results might be biased and unrepresentative in general. In addition, because the questionnaire survey was analyzed cumulatively, the answers of participants who frequently attended the seminars might have had a greater 
Table 7 Representative answers of each profession to Q8 ("Why do you think so? Please explain the reasons for this")

\begin{tabular}{|c|c|}
\hline Profession & Explanations \\
\hline Nurses & $\begin{array}{l}\text { Reasons for "Yes" } \\
\text { - I could increase my knowledge and give better advice to patients. } \\
\text { - I could talk to patients about diabetes care more concretely with certain evidence in a persuasive manner. } \\
\text { - I could be more confident when I answered questions from patients. } \\
\text { - Now I have more interest in diabetes. } \\
\text { - Sometimes I recall what I learnt from the lecture and use the knowledge in my daily tasks. } \\
\text { Reasons for "No" } \\
\text { - Lectures were helpful but I did not have a chance to use the knowledge I gained. } \\
\text { - I am still inexperienced and I haven't had many opportunities to aid patients with diabetes. } \\
\text { Reasons for "Not sure" } \\
\text { - I was motivated by the seminar but not yet reaching the level of behavior change. } \\
\text { - I think I could gain more knowledge but could not make use of it in a real setting. } \\
\text { - I was not in charge of caring for patients with diabetes. }\end{array}$ \\
\hline Pharmacists & $\begin{array}{l}\text { Reasons for "Yes" } \\
\text { - Now I understand examinations regarding diabetes, of which I did not know much. } \\
\text { - I could understand how other professions educate and advise patients with diabetes. } \\
\text { Reasons for "No" } \\
\text { Not available } \\
\text { Reasons for "Not sure" } \\
\text { Not available }\end{array}$ \\
\hline Physiotherapists & $\begin{array}{l}\text { Reasons for "Yes" } \\
\text { - With knowledge of diabetes, I was able to teach exercise therapy to patients more confidently. } \\
\text { - I became more considerate about diabetic complications and risks when I teach exercise therapy. } \\
\text { - During exercise therapy, sometimes patients ask me about diet therapy. Thanks to the seminars, I was able to } \\
\text { answer their questions. } \\
\text { Reasons for "No" } \\
\text { Not available } \\
\text { Reasons for "Not sure" } \\
\text { Not available }\end{array}$ \\
\hline $\begin{array}{l}\text { Clinical laboratory } \\
\text { technicians }\end{array}$ & $\begin{array}{l}\text { Reasons for "Yes" } \\
\text { - Previously, I simply analyzed blood samples, but now I am trying to understand patients' comprehensive condition } \\
\text { by checking the results of blood examinations. } \\
\text { - When I collect blood samples, patients often ask me various things. I think I am now able to answer more } \\
\text { correctly by using knowledge that I gained in a lecture. } \\
\text { Reasons for "No" } \\
\text { - Given the nature of my profession, I do not engage in the treatment of diabetes. } \\
\text { Reasons for "Not sure" } \\
\text { - Just after the seminar, I became interested in patients' examination results. However, in my busy duty schedule, my } \\
\text { interests have gradually faded as time goes by. } \\
\text { - In a daily practice, I don't have so much of a chance to be involved in patients' care. }\end{array}$ \\
\hline Dieticians & $\begin{array}{l}\text { Reasons for "Yes" } \\
\text { - The knowledge I gained in the lectures enriched my explanations to patients during diet counselling. } \\
\text { - By checking medication or exercise records on the electronic chart, I became able to understand the backgrounds } \\
\text { of patients. } \\
\text { - I could learn many things from lectures given by other professions. } \\
\text { - The lecture by a colleague (dietician) was helpful because I seldom had the chance to see my colleague's diet } \\
\text { counselling. }\end{array}$ \\
\hline
\end{tabular}

(Continued) 
Table 7 (Continued).

\begin{tabular}{|l|l|}
\hline Profession & Explanations \\
\hline Reasons for "No" & $\begin{array}{l}\text { Not available } \\
\text { Reasons for "Not sure" } \\
\text { - The lectures were helpful and informative, but I myself keenly realize my lack of knowledge. }\end{array}$ \\
\hline Midwives & $\begin{array}{l}\text { Reasons for "Yes" } \\
\text { - I could understand the pathophysiology of diabetes very well. }\end{array}$ \\
& $\begin{array}{l}\text { - I have been caring for so many expectant mothers with gestational diabetes. The lectures made me think about } \\
\text { Reasons for "No" } \\
\text { Not available } \\
\text { Reasons for "Not sure" } \\
\text { Not available }\end{array}$ \\
\hline Doctors & $\begin{array}{l}\text { Reasons for "Yes" } \\
\text { - I could add knowledge from a field I was not specialized in, and I could improve my explanations to patients. } \\
\text { - By experiencing SMBG, now I understand why patients hate to do it. } \\
\text { - I think I could be more sympathetic to patients who continuously perform SMBG. } \\
\text { Reasons for "No" } \\
\text { Not available } \\
\text { Reasons for "Not sure" } \\
\text { Not available }\end{array}$ \\
\hline
\end{tabular}

Abbreviation: SMBG, Self-monitoring of blood glucose.

influence on the analysis and therefore might bias the results. Third, because there were too few clinical laboratory technicians, midwives, dieticians, and doctors in the sample, our findings may not be representative of these professions.

\section{Conclusion}

The educational diabetes seminars implemented by and for medical professionals were well-received in general; however, they were not effective enough to change all the participants' daily work or attitude toward patients. Knowledge provided in the seminars may not lead to direct improvement in medical care for patients with diabetes; however, it might lead to mutual understanding between professions and thus contribute to better medical care for patients eventually. Because interactive participatory seminars received favorable comments, this format should be adopted to make seminars more attractive. Long-term improvements in the health of individuals with diabetes depend on effective professional development. ${ }^{25}$ Thus, further research such as longitudinal follow-up studies are required to evaluate the long-term effects of appropriate training of health professionals on the glycemic control of patients.

\section{Abbreviation list}

CDEJ, certified diabetes educators in Japan.

\section{Acknowledgments}

The author would like to thank all the lecturers and medical professionals at Sanno Hospital for organizing and facilitating the diabetes seminars, and Ms. Aya Iwai for her special cooperation.

\section{Disclosure}

The author reports no conflicts of interest in this work.

\section{References}

1. International Diabetes Federation. IDF Diabetes Atlas. 8th ed; 2017. Available from: http://www.diabetesatlas.org/. Accessed May 10, 2019.

2. Kishimoto M, Noda M. The difficulties of interprofessional teamwork in diabetes care: a questionnaire survey. $J$ Multidiscip Healthc. 2014;7:333-339. doi:10.2147/JMDH.S46910

3. Dounis G, Ditmyer M, Vanbeuge S, et al. Interprofessional faculty development: integration of oral health into the geriatric diabetes curriculum, from theory to practice. $J$ Multidiscip Healthc. 2013;7:1-9. doi:10.2147/JMDH.S54851

4. Ritholz MD, Beverly EA, Abrahamson MJ, Brooks KM, Hultgren BA, Weinger K. Physicians' perceptions of the type 2 diabetes multidisciplinary treatment team: a qualitative study. Diabetes Educ. 2011;37:794-800. doi:10.1177/0145721711423320 
5. Warrington L, Ayers P, Baldwin AM, et al. Implementation of a pharmacist-led, multidisciplinary diabetes management team. Am J Health Syst Pharm. 2012;69:1240-1245. doi:10.2146/ajhp110297

6. Minamizono S, Hasegawa H, Hasunuma N, et al. Physician's perceptions of interprofessional collaboration in clinical training hospitals in Northeastern Japan. J Clin Med Res. 2013;5:350-355.

7. Curran VR, Sharpe D, Forristall J. Attitudes of health sciences faculty members towards interprofessional teamwork and education. Med Educ. 2007;41:892-896. doi:10.1111/med.2007.41.issue-9

8. Saint-Pierre C, Herskovic V, Sepúlveda M. Multidisciplinary collaboration in primary care: a systematic review. Fam Pract. 2018;35:132-141. doi:10.1093/fampra/cmx085

9. Chwastiak LA, Jackson SL, Russo J, et al. A collaborative care team to integrate behavioral health care and treatment of poorly-controlled type 2 diabetes in an urban safety net primary care clinic. Gen Hosp Psychiatry. 2017;44:10-15. doi:10.1016/j.genhosppsych.2016.10.005

10. Jones SL. Diabetes case management in primary care: the New Brunswick experience and expanding the practice of the certified diabetes educator nurse into primary care. Can $J$ Diabetes. 2015;39:322-324. doi:10.1016/j.jcjd.2014.12.006

11. McGill M, Blonde L, Chan JCN, et al. The interdisciplinary team in type 2 diabetes management: challenges and best practice solutions from real-world scenarios. J Clin Transl Endocrinol. 2016;7:21-27.

12. Bright DR, Kroustos KR, Thompson RE, Swanson SC, Terrell SL, DiPietro NA. Preliminary results from a multidisciplinary university-based disease state management program focused on hypertension, hyperlipidemia, and diabetes. $J$ Pharm Pract. 2012;25:130-135. doi:10.1177/0897190011420725

13. Pimazoni-Netto A, Rodbard D, Zanella MT; Diabetes Education and Control Group. Rapid improvement of glycemic control in type 2 diabetes using weekly intensive multifactorial interventions: structured glucose monitoring, patient education, and adjustment of therapy: a randomized controlled trial. Diabetes Technol Ther. 2011;13:997-1004. doi:10.1089/dia.2011.0054

14. Rasekaba TM, Graco M, Risteski C, et al. Impact of a diabetes disease management program on diabetes control and patient quality of life. Popul Health Manag. 2012;15:12-19. doi:10.1089/pop.2011.0002
15. Codispoti C, Douglas MR, McCallister T, et al. The use of a multidisciplinary team care approach to improve glycemic control and quality of life by the prevention of complications among diabetic patients. J Okla State Med Assoc. 2004;97:201-204.

16. Sadur CN, Moline N, Costa M, et al. Diabetes management in a health maintenance organization. Efficacy of care management using cluster visits. Diabetes Care. 1999;22:2011-2017. doi:10.2337/diacare.22.12.2011

17. Watts SA, Sood A. Diabetes nurse case management: improving glucose control: 10 years of quality improvement follow-up data. Appl Nurs Res. 2016;29:202-205. doi:10.1016/j.apnr.2015.03.011

18. Herath C, Zhou Y, Gan Y, Nakandawire N, Gong Y, Lu Z. A comparative study of interprofessional education in global health care: a systematic review. Medicine. 2017;96:e7336. doi:10.1097/ MD.0000000000007336

19. Gilbert JH, Yan J, Hoffman SJ. A WHO report: framework for action on interprofessional education and collaborative practice. $J$ Allied Health. 2010;39:196-197.

20. McGill M, Felton AM. Global partnership for effective diabetes management. New global recommendations: a multidisciplinary approach to improving outcomes in diabetes. Prim Care Diabetes. 2007;1:49-55. doi:10.1016/j.pcd.2006.07.004

21. Certification Board for Diabetes Educators in Japan (in Japanese). Available from: http://www.cdej.gr.jp/. Accessed May 10, 2019.

22. Burke SD, Sherr D, Lipman RD. Partnering with diabetes educators to improve patient outcomes. Diabetes Metab Syndr Obes. 2014;7:45-53. doi:10.2147/DMSO.S40036

23. Peyrot M, Burns KK, Davies M, et al. Diabetes attitudes wishes and needs 2 (DAWN2): a multinational, multi-stakeholder study of psychosocial issues in diabetes and person-centred diabetes care. Diabetes Res Clin Pract. 2013;99:174-184. doi:10.1016/j. diabres.2012.11.016

24. Kishimoto M, Noda M. The factors that limit activities of certified diabetes educators in Japan: a questionnaire survey. Springerplus. 2014;3:611. doi:10.1186/2193-1801-3-611

25. Apfel J, Coles C, Crace C, et al. Training and professional development in diabetes care. Diabet Med. 1996;13:S65-S76.

\section{Publish your work in this journal}

The Journal of Multidisciplinary Healthcare is an international, peerreviewed open-access journal that aims to represent and publish research in healthcare areas delivered by practitioners of different disciplines. This includes studies and reviews conducted by multidisciplinary teams as well as research which evaluates the results or conduct of such teams or healthcare processes in general. The journal covers a very wide range of areas and welcomes submissions from practitioners at all levels, from all over the world. The manuscrip management system is completely online and includes a very quick and fair peer-review system. Visit http://www.dovepress.com/testimonials. php to read real quotes from published authors. 